\title{
Growth and lipid production of Rhodotorula glutinis R4, in comparison to other oleaginous yeasts
}

\author{
D. Daniela Maza ${ }^{\mathrm{a}}$, Silvana C. Viñarta ${ }^{\mathrm{b} * *}$, Ying Su${ }^{\mathrm{c}}$, José Manuel Guillamón ${ }^{\mathrm{c}}$, Manuel J. Aybar ${ }^{\mathrm{a}, \mathrm{d}, *}$ \\ ${ }^{a}$ Instituto Superior de Investigaciones Biológicas (INSIBIO, CONICET-Universidad Nacional de Tucumán), Tucumán, Argentina \\ ${ }^{\mathrm{b}}$ Planta Piloto de Procesos Industriales Microbiológicos (PROIMI-CONICET), Tucumán, Argentina \\ ' Instituto de Agroquímica y Tecnología de Alimentos (IATA), Consejo Superior de Investigaciones Científicas (CSIC), Valencia, Spain \\ d Instituto de Biología "Dr. Francisco D. Barbieri”, Facultad de Bioquímica, Química y Farmacia de la Universidad Nacional de Tucumán, Tucumán, Argentina
}

\section{A R T I C L E I N F O}

\section{Keywords:}

Rhodotorula

Microbial lipids

Single cell oils

Biodiesel

Oleaginous yeast

Antarctica

Third generation biodiesel

\begin{abstract}
A B S T R A C T
Some Rhodotorula spp. have been characterized as oleaginous yeasts. Under certain culture conditions they can accumulate neutral lipids, which are mainly triglycerides (TAG). Microbial TAG that can be used as raw material for biodiesel synthesis are attractive for the biofuel industry. In this study, the ability to synthesize lipids of Rhodotorula glutinis R4, isolated in Antarctica, was compared with eight strains belonging to the genera Rhodotorula and Yarrowia with the aim of proposing a novel source of oils for biodiesel synthesis. All strains were cultured under nitrogen (N) limiting conditions and an excess of carbon (C) in the culture medium. We found that yeasts accumulated between 9-48.9\% (w/w) of lipids. Among them, R. glutinis R4 showed the highest growth $\left(14 \mathrm{~g} \mathrm{~L}^{-1}, \mu \max 0,092 \mathrm{~h}^{-1}\right)$ and lipid production $\left(7 \mathrm{~g} \mathrm{~L}^{-1} ; 47 \% \mathrm{w} / \mathrm{w}\right)$. Microbial oils produced by $R$. glutinis R4 are similar to vegetable oils, with $61 \%$ of oleic acid, indicating that it is adequate for biodiesel synthesis. Our results demonstrate that biodiesel derived from R. glutinis R4 complies with international fuel standards ASTM D6751 and EN 14214. Therefore, this work demonstrates that Rhodotorula glutinis R4 is a novel and valuable source of microbial oils for biodiesel synthesis.
\end{abstract}

\section{Introduction}

Because of the constant search for alternative energy sources to decrease dependence on petroleum-based fuel, biofuel production has emerged as a key player. Thereby, significant research is being performed on the production of biofuels from renewable sources, particularly in biodiesel production (Li et al., 2007). Currently, soy, palm, jatropha, rapeseed and sunflower seeds, among others, are the main source of oils used for biodiesel synthesis. This type of raw material has numerous disadvantages, the most important being high production costs, negative environmental impact, and direct competition with the production and availability of animal and human food. Additionally, vegetable oil production for biodiesel promotes deforestation and encourages monocultures. Moreover, large planting areas are required and yields are affected by weather conditions, among other limitations. Due to the above-mentioned reasons, social movements have campaigned against the use of this type of biofuels because of its negative effects on wild ecosystems (Elshout et al., 2019).

Nowadays there is great interest in finding new sources of lipids that can be used for biodiesel production (Beopoulos and Nicaud, 2012). A viable solution is the use of microbial oils. These oils are effectively synthesized by many microorganisms such as bacteria, yeasts, filamentous fungi and unicellular algae (Meng et al., 2009). Numerous studies conducted in this area have shown that, under certain conditions, some organisms have the ability to produce and accumulate lipids. When this ability to accumulate lipids is $\geq 20 \%$ (w/w) with respect to their biomass, they are considered oleaginous microorganisms (Donot et al., 2014). In particular, these lipids accumulate in the cytoplasm, specifically within the lipid bodies (LB) (Park et al., 2017). Additionally, the production of these lipids starts at the end of the exponential growth phase and is more intense during the stationary phase.

\footnotetext{
Abbreviations: FAME, Fatty Acyl Methyl Esters; FA, fatty acids; SCO, single cell oils; FID, flame ionization detector; TAG, triacylglycerol; SFA, saturated fatty acids;

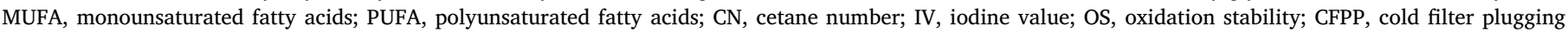
property; HHV, high heating value; AUC, area under the curve; YAN, yeast assimilable nitrogen

* Corresponding author at: INSIBIO (CONICET-UNT), Chacabuco 461, T4000ILI, San Miguel de Tucumán, Tucumán, Argentina.

** Corresponding author at: PROIMI-CONICET, Av. Manuel Belgrano and Pje. Caseros, T4001MVB, San Miguel de Tucumán, Argentina.

E-mail addresses: scvinarta@hotmail.com (S.C. Viñarta), mjaybar@fbqf.unt.edu.ar (M.J. Aybar).
} 
Presently, oleaginous yeasts are being evaluated as oil factories due to the advantages they present compared to vegetable oils. They have a short life cycle and are less affected by seasons and climate, they require less labor and microbial oil production is easier to scale up. In addition, no extensive cultivation areas are required and microbial oil production is independent of geographic location (Liang and Jiang, 2013). In general, oleaginous yeasts belong to the genera Lipomyces, Cryptococcus, Trichosporon and Yarrowia as well as Rhodotorula (Rhodosporidium). The genus Rhodotorula, which includes red pigmented yeasts, belongs to the Basidiomycota division. It was found and isolated from different sources such as air, seawater, fruits and soil (Kurtzman et al., 2011). Today, this genus is being intensively studied since it has the natural ability to produce many different compounds of industrial interest besides lipids. Moreover, the above yeasts also synthesize carotenoids, enzymes and terpenes (Park et al., 2017). Up to now, several Rhodotorula spp. have been recognized as oleaginous yeasts, as they can accumulate between $40-70 \%(w / w)$ of intracellular neutral lipids under nitrogen limitation and simultaneous excess of carbon source (Viñarta et al., 2016). However, it has been reported that nitrogen limitation is not the only condition that induces lipogenesis. Sulphate and phosphate limitation in the culture medium are also influencing factors that may affect lipid biosynthesis. All the above conditions may affect cell proliferation rate and could result in low biomass yield. In brief, there are numerous factors that affect lipid content and fatty acid composition, e.g. environmental factors, including aeration, $\mathrm{pH}$, temperature, inoculum size, incubation period, medium composition and culture conditions. However, the most important factor is the microorganism used for lipid production (Subramaniam et al., 2010).

Due to the wide variety of factors that affect the production of lipids, different strategies for productivity optimization have been studied. In this regard, it has been demonstrated that the lipids synthetized by Rhodotorula spp. can be used as feedstock for biodiesel production, and that they can also be employed as a source of nutritionally valuable fatty acids (FA) (Sitepu et al., 2014).

During the last decade, interest has been focused on selecting new strains as promising lipid producers as well as developing new strategies to increase lipid production. These strategies include oxygenation conditions, temperature, $\mathrm{pH}$ and the optimization of the entire process itself. Progress has also been made in the development of molecular biology tools, which will increase the understanding of the metabolic pathways taking place in the control of lipid synthesis, accumulation and degradation. All this knowledge will provide the necessary tools to optimize the industrial process of lipid production by microorganisms (Lyman et al., 2019).

In addition, Rhodotorula species have proved to have a biotechnological advantage over other oleaginous yeasts because of their ability to grow on inexpensive substrates. They are capable of metabolizing many compounds used as carbon sources such as sugar (mono-, di-, or poly-saccharides), organic acids, glycerol, raw materials, industrial byproducts and wastewaters (Park et al., 2017), which reduces total production costs. Microbial lipids, also known as single cell oils (SCO), are considered an important alternative source of lipids for several biotechnological applications, including biofuel and pharmaceutical industries. Among Rhodotorula spp., $R$. glutinis has been identified as an excellent lipid and carotenoid producer. Therefore in this work we decided to compare the ability for lipid biosynthesis of the cold-adapted oleaginous yeast Rhodotorula glutinis R4, isolated in Antarctica by our laboratory, with eight other yeast strains, including Rhodotorula spp. and Yarrowia spp. Our results suggest that Rhodotorula glutinis R4 could be a novel and valuable source of microbial oils for biodiesel synthesis.

\section{Materials and methods}

\subsection{Yeasts strains}

Nine yeast strains, belonging to the genus Rhodotorula ( $R$. toruloides
Y-1091, Y-6987, Y-6985, Y-1588 and Y-17092; R. mucilaginosa RCL11, R. glutinis Y-34 and R4) and Yarrowia (Y. lipolytica, Y-323), were analyzed and compared in this work. Some strains ( $R$. toruloides Y-1091, $R$. toruloides $Y$-1588, R. toruloides Y-6987 and R. glutinis R4) had been previously characterized as oleaginous yeasts (Osorio-González et al., 2019; Turcotte and Kosaric, 1989; Viñarta et al., 2016; Zhu et al., 2012) while the other five yeast-strains had not been previously reported and/ or investigated as oleaginous yeasts.

$R$. glutinis R4 was isolated from soil samples collected in Antarctica, at Caleta Potter, 25 de Mayo Island $\left(62^{\circ} 14^{\prime} 18^{\prime \prime} \mathrm{S}, 58^{\circ} 40^{\prime} 00^{\prime \prime} \mathrm{W}\right.$ ) (Rovati et al., 2013). This strain was previously characterized as a psychrotolerant oleaginous yeast (Viñarta et al., 2016), while R. mucilaginosa RCL11 was isolated from wastewater sediment samples collected from a copper filter mining plant located in the province of Tucumán, Argentina (Villegas et al., 2005). The R4 and RCL11 strains were obtained from the Microbiological Resources Center Culture Collection (MIRCEN) of the PROIMI-CONICET research institute, San Miguel de Tucumán, Argentina.

The other seven strains (Y-1091, Y-6987, Y-6985, Y-1588, Y-17092, Y- 323 and Y-34) used in this work were a generous gift from the ARS Culture Collection.

\subsection{Media and culture conditions}

Stock cultures were kept on solid YM-agar (in $\mathrm{g} \mathrm{L}^{-1}$ : yeast extract 3 , malt extract 3 , peptone 5 , dextrose 10 , agar 20 ) plates at $25^{\circ} \mathrm{C}$ for $48 \mathrm{~h}$ and then maintained at $4{ }^{\circ} \mathrm{C}$ and sub-cultured twice a month.

Yeasts were aerobically cultured in the N-limited glucose-based medium GMY ( $\mathrm{g} \mathrm{L}^{-1}$ : $\mathrm{KH}_{2} \mathrm{PO}_{4} 8$; $\mathrm{MgSO}_{4} .7 \mathrm{H}_{2} \mathrm{O}$ 0.5; yeast extract 3). Glucose was used as carbon (C) source, which was added to the culture at a final concentration of $40 \mathrm{~g} \mathrm{~L}^{-1}(\mathrm{C} / \mathrm{N}=40)$, while the yeast extract ( $\mathrm{N}$ total $11 \%$ ) was used as the only $\mathrm{N}$ source. Yeast-inocula were prepared by introducing a loop of one colony from the GMY agar into $50 \mathrm{~mL}$ of GMY medium. The $\mathrm{pH}$ of medium was adjusted to 5.5 before inoculation. After $24 \mathrm{~h}$ of incubation at $25^{\circ} \mathrm{C}$ and $250 \mathrm{rpm}$, the cultures of each yeast were used to inoculate $200 \mathrm{~mL}$ of GMY medium, reaching an initial OD $(\lambda=600 \mathrm{~nm}$ ) of approximately 0.1 (corresponding to a starting cell number of $1 \times 10^{6}$ cells $/ \mathrm{mL}$ ). These cultures were incubated in Erlenmeyer flasks $(500 \mathrm{~mL})$, fitted with cotton, agitated at $250 \mathrm{rpm}$, and incubated aerobically at $25^{\circ} \mathrm{C}$. Samples were taken for analytical determinations (biomass and lipid analysis) after 120 and $144 \mathrm{~h}$ of culture. Yeast growth over time was evaluated by OD $(\lambda=600 \mathrm{~nm})$, with samples of the same volume of culture being taken at different times. Samples were collected every hour during the first $12 \mathrm{~h}$, after which they were collected every 12 or $24 \mathrm{~h}$.

With the exception of glucose, all media were sterilized in an autoclave at a temperature of $121{ }^{\circ} \mathrm{C}$ and $1 \mathrm{~atm}$ for $20 \mathrm{~min}$. The glucose was filtered under sterilization conditions and then added to the previously sterilized medium.

For all analytical determinations, samples were taken under sterile conditions at different culture times as described below. All experiments were carried out in triplicate.

\subsection{Residual glucose and nitrogen assimilation analysis}

Residual glucose and nitrogen were analyzed in the supernatant of samples throughout. The samples were taken at the beginning and at different time points throughout the $144 \mathrm{~h}$ of culture time. Following sterile sampling and centrifugation, the supernatant was collected for glucose and nitrogen content measurements and stored at $-20^{\circ} \mathrm{C}$. The amount of sugar and nitrogen consumed was calculated by subtracting the residual amount present in the supernatant from the total amount determined in the initial culture.

Residual glucose was determined by analytical HPLC, which was carried out in a Surveyor Plus Chromatograph (Thermo Fisher Scientific, Waltham, MA) equipped with a refraction index detector, an 
autosampler and a UV-vis detector. Before injection, samples were centrifuged at maximum speed for $10 \mathrm{~min}$, diluted 10 -fold only if necessary, and filtered through $0.22 \mu \mathrm{m}$ pore size nylon filters (Micron Analytica, Spain). A total volume of $25 \mu \mathrm{L}$ was injected into a HyperREZ XP Carbohydrate $\mathrm{H}+8 \mathrm{~mm}$ column (Thermo Fisher Scientific) assembled to its correspondent guard. The mobile phase was $1.5 \mathrm{mM}$ $\mathrm{H}_{2} \mathrm{SO}_{4}$ with a flux of $0.6 \mathrm{~mL} \min ^{1}$ and a column temperature of $50^{\circ} \mathrm{C}$. The concentration of each compound was calculated using external standards. Each sample was injected in duplicate.

Determination of nitrogen assimilation was evaluated in the supernatant fluid of culture samples according to published protocols by Gómez-Alonso et al. (2007), and some modifications previously described by Su et al. (Su et al., 2019). Results were expressed in mg N $\mathrm{L}^{-1}$. Derivatization was carried out in a volume of supernatant followed by UPLC (Dionex Ultimate 3000, Thermo Fisher Scientific, Waltham, MA) equipped with a Kinetex2.6 $\mu \mathrm{m}$ C18 100A column (Phenomenex, Torrance, CA, USA) and Accucore C18 $(10 \times 4.6 \mathrm{~mm}$; $2.6 \mu \mathrm{m})$ defender guards (Thermo Fisher Scientific, Waltham, MA). Before injecting, samples were filtered by $0.22 \mu \mathrm{m}$ pore size nylon filters (Micron Analytica, Spain). This technique allowed quantifying the concentration of free amino acids and ammonia present in the supernatant of samples, supplied by yeast extract which is the only source of nitrogen in the GMY media.

The compounds were identified according to the retention times and UV-vis spectral characteristics of standards and were quantified using the internal standard method (Gómez-Alonso et al., 2007).

\subsection{Biomass yield determination by dry cell weight}

Biomass dry weight ( $\mathrm{g}$ DW/L) was determined gravimetrically (Viñarta et al., 2016). Biomass was removed by centrifuging culture broth, washed twice with the same volume of distilled water and then dried at $105^{\circ} \mathrm{C}$ to constant weight.

\subsection{Lipids analysis}

Lipid extraction of yeasts was carried out from lyophilized and pulverized biomass (Viñarta et al., 2016) with solvents (chloroform: methanol, $2: 1 ; \mathrm{v}: \mathrm{v}$ ) and constant stirring at room temperature according to standard methodology (Bligh and Dyer, 1959. After that, the samples were centrifuged at $14000 \times g$ for $10 \mathrm{~min}$ at $4{ }^{\circ} \mathrm{C}$, and the organic phase of the supernatant containing lipids was recovered and completely evaporated. Lipids were gravimetrically determined overnight at $105^{\circ} \mathrm{C}$ until constant weight. Samples were collected after 120 and $144 \mathrm{~h}$ of culture.

\subsection{Calculation of the specific yield coefficient and volumetric productivity}

The weights of lipids, dry biomass and glucose consumed were used to determine lipid/glucose $\left(\mathrm{Y}_{\mathrm{L} / \mathrm{S}}\right)$, biomass/glucose $\left(\mathrm{Y}_{\mathrm{X} / \mathrm{S}}\right)$, and lipid/biomass yield $\left(\mathrm{Y}_{\mathrm{L} / \mathrm{X}}\right)$ coefficients, expressed as $\mathrm{g} \mathrm{g}^{-1}$. Productivity of biomass $\left(\mathrm{Q}_{\mathrm{X}}\right)$ and lipids $\left(\mathrm{Q}_{\mathrm{L}}\right)$ was calculated by dividing their concentrations over time of the corresponding culture, expressed as $\mathrm{g} \mathrm{L}^{-1} \mathrm{~h}^{-1}$.

\subsection{Fluorescence microscopy}

The lipid bodies were observed by fluorescence microscopy in an Olympus BX53 microscope equipped with a DP71 camera. Yeasts cells were stained with Nile Red (9-diethylamino-5H-benzo[ $\alpha]$ phenoxazine5-one) according to the protocol described by Kimura et al. (2004) (Kimura et al., 2004). S. cerevisiae ATCC32051 was used as a negative control and Rhodotorula toruloides Y-1091 and Y-6987 were included as positive controls (Turcotte and Kosaric, 1989; Zhu et al., 2012).

\subsection{Determination of TAG by thin layer chromatography (TLC)}

Lipids were analyzed by thin layer chromatography (TLC) according to Álvarez et al. (Alvarez et al., 2008). The extracts were concentrated at $50 \%$ of their original volume, subjected to TLC using plates silica gel 60 F254 Aluminum sheets $20 \times 20 \mathrm{~cm}$ (Merck Millipore), and developed in hexane: diethyl ether: acetic acid (90:10:1, by vol.) as system solvent for TAG analysis. Olive and soybean oils were included as control of vegetable TAG. TLC plates were stained with iodine vapor (Alvarez et al., 2008) and then TLC plates were photographed.

\subsection{Fatty acids composition}

The oils were analyzed by GC-FID in order to determine the relative composition of the fatty acids (FA). After lipid extraction, oil samples were subjected to methanolysis as reported by Amaretti et al. (2010) and fatty acyl methyl esters (FAME) were analyzed by GC using an Agilent Technologies (Model 6890) equipped with a flame ionization detector (FID) and automatic injector, and an HP-5 capillary column ( $30 \mathrm{mx} 0.32 \mathrm{~mm}$ id, $0.25 \mu \mathrm{m}$ ). Carrier gas was $\mathrm{N}_{2}$ with a flow rate of $15.0 \mathrm{~mL} \min ^{-1}$. The injection temperature was $270{ }^{\circ} \mathrm{C}$; initial temperature was $40^{\circ} \mathrm{C}$, increasing to $190^{\circ} \mathrm{C}$ at a rate of $23^{\circ} \mathrm{C} \mathrm{min}^{-1}$ and holding for $4 \mathrm{~min}$, then increasing to $290^{\circ} \mathrm{C}$ at a rate of $8{ }^{\circ} \mathrm{C} \mathrm{min}{ }^{-1}$ and holding for $5 \mathrm{~min}$. Detector temperature was $300^{\circ} \mathrm{C}$. Fatty acids were identified by comparing retention times with those of methylated standards (99\% pure; Sigma- Aldrich), and results were expressed as a percentage of the total fatty acids identified (Amaretti et al., 2010). The determinations were performed for three independent replicates of the samples.

\subsection{Biodiesel quality estimation using FAME data}

The quality of the biodiesel produced by $R$. glutinis R4 was estimated using the FAME profile. Some important physical properties such as cetane number (CN), saponification value (SV), iodine value (IV), degree of unsaturation (DU), long-chain saturation factor (LCSF), cold filter plugging point (CFPP), oxidative stability (OS), high heating value (HHV), kinematic viscosity ( $\nu$ ) and density $(\rho)$ were calculated by previously reported empirical equations using the fatty acids composition (Patel et al., 2016).

$$
\begin{aligned}
& S V=\sum 560 \times\left(\frac{\% F C}{M}\right) \\
& I V=\sum 254 \times D B \times\left(\frac{\% F C}{M}\right) \\
& C N=46.3+\frac{5458}{S V}-(0.255 \times I V) \\
& D U(\%)=M U F A+(2 \times P U F A) \\
& L C S F=(0.1 \times C 16)+(0.5 \times C 18) \\
& C F F P=(3.417 \times L C S F)-16.477 \\
& O S=\frac{117.9295}{(w t \% C 18: 2+w t \% C 18: 3)}+2.5905 \\
& H H V=49.43-(0.41 \times S V)-(0.015 \times S V) \\
& v=e^{\left[-\frac{12}{503}+2.496 \times \ln \left(\sum M\right)-0.178 \times \sum D B\right]} \\
& \rho=0.8463+\frac{4.9}{\sum M}+0.0018 \times \sum D B
\end{aligned}
$$

where $\mathrm{M}$ is the molecular mass of each fatty acid component, DB equals to the number of double bonds, FC is the \% of each fatty acid component, MUFA is the weight $\%$ of monounsaturated fatty acids and PUFA corresponds to the weight $\%$ of polyunsaturated fatty acid. 


\subsection{Statistical data processing}

All the experiments were carried out at least in triplicate. Physiological data and correlation tests were analyzed with the Sigma Plot 12.5 software and results are expressed as mean and standard deviation. In order to evaluate statistical significance, tailed t-Student's test was applied with a p-value of $\leq 0.05$. Means were compared and analyzed using one-way analysis of variance (ANOVA) with Tukey-Kramer multiple comparisons tests carried out at the $\alpha=0.05$ level of significance.

\section{Results and discussion}

\subsection{Lipid production by yeasts}

A comparative study of lipid accumulation was performed for nine yeast strains. One of the objectives of this work was to compare the

A- Rhodotorula toruloides Y-1091

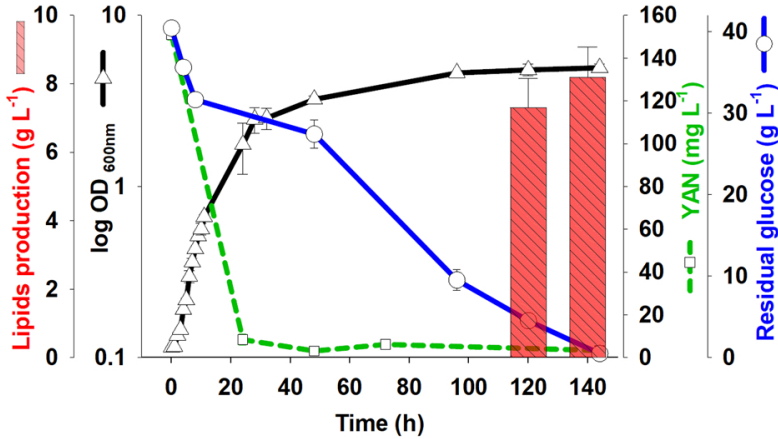

C- Rhodotorula glutinis R4

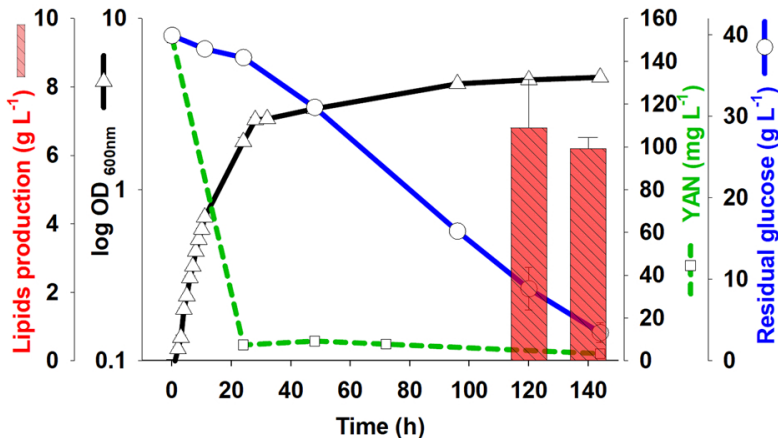

E- Rhodotorula toruloides Y-1588

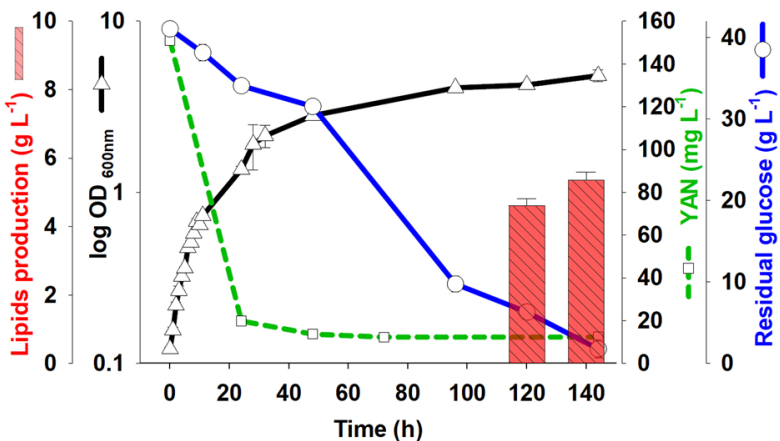

intracellular lipid production by $R$. glutinis $\mathrm{R} 4$ (a strain isolated from Antarctica, Argentina) against yeasts available in collections. Rhodotorula spp. and Yarrowia spp. were evaluated and considered in this work since in both genera several species are widely recognized as oleaginous yeasts. $R$. glutinis R4 was previously characterized as an oleaginous yeast by Viñarta et al. (Viñarta et al., 2016). Likewise, Y1091, Y-1588 and Y-6987 strains were previously reported as oleaginous yeasts and used as reference strains and positive controls in this work (Osorio-González et al., 2019; Turcotte and Kosaric, 1989; Zhu et al., 2012).

All yeasts were grown in liquid GMY medium in flasks and incubated at $25^{\circ} \mathrm{C}$ under aerobic conditions; meanwhile, they were characterized using the classic growth curves for $144 \mathrm{~h}$. Yeasts showed typical growth phases, logarithmic and stationary phase (Fig. 1). Lipids production was evaluated after 120 and $144 \mathrm{~h}$ of culture for each strain. Results showed that there were no statistically significant differences in lipid production after 120 and $144 \mathrm{~h}$ of culture of yeasts (Fig. 1). This

\section{B- Rhodotorula toruloides Y-6987}

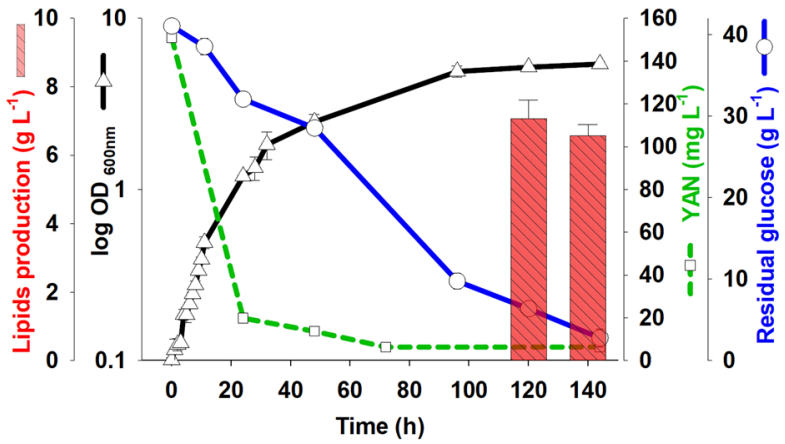

D- Rhodotorula toruloides Y-6985

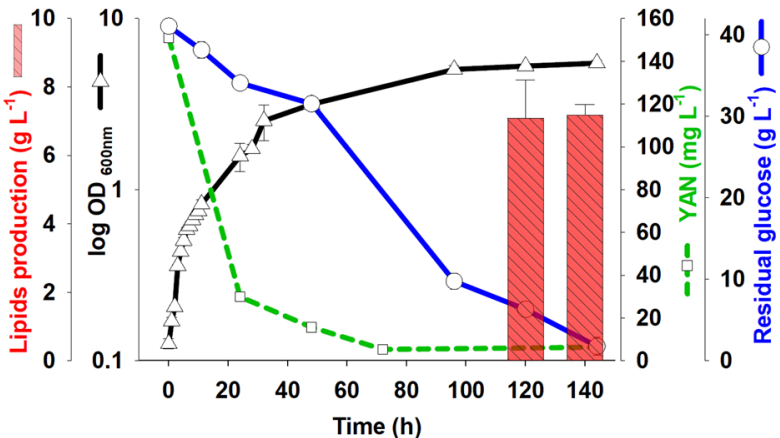

F- $\quad$ Rhodotorula toruloides Y-34

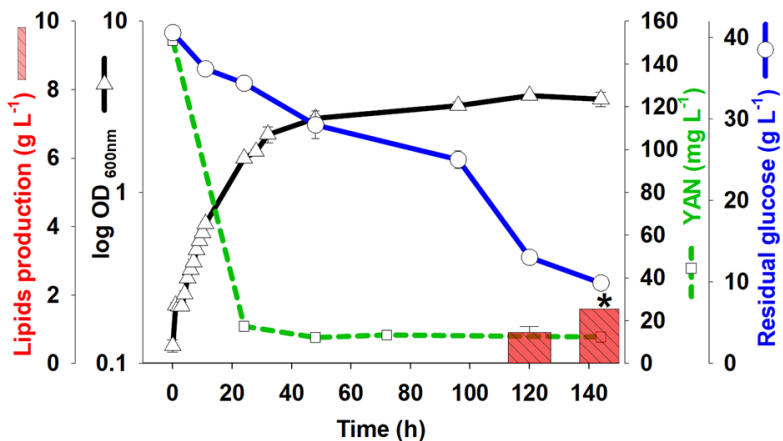

Fig. 1. Growth $\left(\triangle ; \log \mathrm{OD}_{600 \mathrm{~nm}}\right.$ ), residual glucose $\left(\mathrm{O} ; \mathrm{g} \mathrm{L}^{-1}\right)$, YAN (Yeast Assimilable Nitrogen; $\square$; $\left.\mathrm{mg} \mathrm{N} \mathrm{L}^{-1}\right)$, lipids production $\left(\mathrm{g} \mathrm{L}^{-1}\right.$; bars) after 120 and $144 \mathrm{~h}$ of culture in GMY medium with glucose as carbon source. A- Rhodotorula toruloides Y-1091. B- Rhodotorula toruloides Y-6987. C- Rhodotorula glutinis R4. DRhodotorula toruloides Y-6985. E- Rhodotorula toruloides Y-1588. F- Rhodotorula glutinis Y-34. Data are mean \pm standard deviation (error bars) of three independent experiment. The asterisk $(*)$ indicate that the difference in lipid production between 120 and $144 \mathrm{~h}$ are statistically significant $(\mathrm{p} \leq 0.05)$. 
Table 1

Biomass and lipid production by Rhodotorula spp. and Yarrowia spp. growth in GMY at $25^{\circ} \mathrm{C}$ during $120 \mathrm{~h}$.

\begin{tabular}{|c|c|c|c|c|}
\hline Strains & $\begin{array}{l}\text { Biomass } \\
\left(\mathrm{g} \mathrm{L}^{-1}\right)\end{array}$ & $\begin{array}{l}\text { Lipids } \\
\left(\mathrm{g} \mathrm{L}^{-1}\right)\end{array}$ & $\begin{array}{l}\text { Lipids } \\
(\%)\end{array}$ & $\begin{array}{l}\mathrm{Y}_{\mathrm{L} / \mathrm{X}} \\
\left(\mathrm{g} \mathrm{g}^{-1}\right)\end{array}$ \\
\hline R. toruloides Y-1091 & $14.900 \pm 1.003^{\mathrm{ab}}$ & $7.30 \pm 0.70^{\mathrm{a}}$ & $48.93 \pm 1.75^{\mathrm{a}}$ & $0.489 \pm 0.018^{a}$ \\
\hline R. toruloides Y-6987 & $16.100 \pm 0.316^{\mathrm{a}}$ & $7.06 \pm 0.54^{\mathrm{a}}$ & $47.10 \pm 3.38^{\mathrm{ab}}$ & $0.471 \pm 0.034^{\mathrm{ab}}$ \\
\hline R. glutinis $R 4$ & $14.325 \pm 0.427^{\mathrm{bc}}$ & $6.80 \pm 1.84^{\mathrm{a}}$ & $47.24 \pm 11.2^{\mathrm{a}}$ & $0.472 \pm 0.112^{\mathrm{a}}$ \\
\hline R. toruloides Y-6985 & $16.125 \pm 0.974^{\mathrm{a}}$ & $7.09 \pm 1.28^{\mathrm{a}}$ & $43.88 \pm 7.02^{\mathrm{ab}}$ & $0.439 \pm 0.070^{\mathrm{ab}}$ \\
\hline R. toruloides Y-1588 & $13.325 \pm 0.499^{c}$ & $4.61 \pm 0.89^{\mathrm{b}}$ & $34.54 \pm 6.03^{\mathrm{b}}$ & $0.345 \pm 0.060^{\mathrm{b}}$ \\
\hline R. mucilaginosa RCL11 & $13.700 \pm 0.440^{\mathrm{bc}}$ & $2.68 \pm 0.36^{\mathrm{bc}}$ & $19.53 \pm 2.52^{c}$ & $0.195 \pm 0.025^{c}$ \\
\hline Y. lipolytica Y-323 & $8.175 \pm 0.525^{\mathrm{d}}$ & $1.18 \pm 0.34^{\mathrm{d}}$ & $14.52 \pm 4.31^{\mathrm{c}}$ & $0.145 \pm 0.043^{c}$ \\
\hline R. toruloides Y-17092 & $9.250 \pm 0.289^{d}$ & $0.85 \pm 0.09^{d}$ & $9.19 \pm 0.98^{c}$ & $0.092 \pm 0.010^{c}$ \\
\hline R. glutinis Y-34 & $9.625 \pm 0.793^{d}$ & $0.90 \pm 0.06^{\mathrm{d}}$ & $9.35 \pm 0.90^{c}$ & $0.093 \pm 0.009^{c}$ \\
\hline Strains & $\begin{array}{l}Y_{L / S} \\
\left(g^{-1}\right)\end{array}$ & $\begin{array}{l}Y_{X / S} \\
\left(g^{-1}\right)\end{array}$ & $\begin{array}{l}\mathrm{Q}_{\mathrm{L}} \\
\left(\mathrm{g} \mathrm{L}^{-1} \mathrm{~h}^{-1}\right)\end{array}$ & $\begin{array}{l}Q_{x} \\
\left(g^{-1} h^{-1}\right)\end{array}$ \\
\hline R. toruloides Y-1091 & $0.203 \pm 0.02^{\mathrm{a}}$ & $0.404 \pm 0.003^{\mathrm{ab}}$ & $0.061 \pm 0.006^{\mathrm{a}}$ & $0.124 \pm 0.008^{\mathrm{ab}}$ \\
\hline R. toruloides Y-6987 & $0.210 \pm 0.02^{\mathrm{a}}$ & $0.469 \pm 0.009^{\mathrm{a}}$ & $0.059 \pm 0.005^{\mathrm{a}}$ & $0.134 \pm 0.003^{\mathrm{a}}$ \\
\hline R. glutinis $R 4$ & $0.219 \pm 0.06^{\mathrm{a}}$ & $0.445 \pm 0.017^{\mathrm{a}}$ & $0.057 \pm 0.015^{\mathrm{a}}$ & $0.119 \pm 0.004^{b c}$ \\
\hline R. toruloides Y-6985 & $0.183 \pm 0.04^{\mathrm{ab}}$ & $0.404 \pm 0.007^{\mathrm{ab}}$ & $0.059 \pm 0.011^{\mathrm{a}}$ & $0.134 \pm 0.008^{a}$ \\
\hline R. toruloides Y-1588 & $0.133 \pm 0.03^{\mathrm{bc}}$ & $0.360 \pm 0.010^{\mathrm{bc}}$ & $0.038 \pm 0.007^{\mathrm{b}}$ & $0.111 \pm 0.004^{c}$ \\
\hline R. mucilaginosa RCL11 & $0.095 \pm 0.01^{\mathrm{cd}}$ & $0.464 \pm 0.026^{\mathrm{a}}$ & $0.022 \pm 0.003^{b c}$ & $0.114 \pm 0.004^{b c}$ \\
\hline Y. lipolytica Y-323 & $0.041 \pm 0.01^{\mathrm{de}}$ & $0.275 \pm 0.010^{\mathrm{d}}$ & $0.010 \pm 0.003^{c}$ & $0.068 \pm 0.004^{\mathrm{d}}$ \\
\hline R. toruloides Y-17092 & $0.028 \pm 0.00^{\mathrm{e}}$ & $0.298 \pm 0.014^{\mathrm{cd}}$ & $0.007 \pm 0.001^{\mathrm{c}}$ & $0.077 \pm 0.002^{\mathrm{d}}$ \\
\hline R. glutinis Y-34 & $0.027 \pm 0.00^{\mathrm{e}}$ & $0.275 \pm 0.007^{\mathrm{cd}}$ & $0.007 \pm 0.001^{\mathrm{c}}$ & $0.080 \pm 0.007^{\mathrm{d}}$ \\
\hline
\end{tabular}

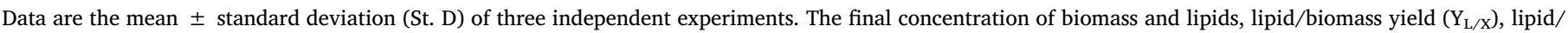

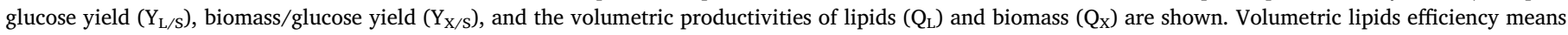
lipids produced by $1 \mathrm{~L}$ of medium. Values followed by the same letters do not differ significantly, Tukey's test, $\alpha=0.05$.

analysis allowed us to determine that $120 \mathrm{~h}$ would be the maximum incubation time to evaluate lipids production. However, RCL11, Y-323 (data no shown) and Y-34 (Fig. 1) exhibited a significantly higher lipid production at $144 \mathrm{~h}$ compared to $120 \mathrm{~h}$ of culture, but their lipid production was lower than $20 \%(\mathrm{w} / \mathrm{w})$.

Growth parameters and lipid synthesis after $120 \mathrm{~h}$ of culture are shown in Table 1. Yeasts accumulated between 9-48.9\% (w/w) of lipids of their dry biomass. The highest percentage of lipids was observed for Y-1091, Y-6987, R4 and Y-6985 strains, and the lowest for Y-34. This work demonstrates for the first time that Y-6985 is an oleaginous yeast because it has the ability to accumulate up to $43.8 \%(\mathrm{w} / \mathrm{w})$ of intracellular lipids, similar to the strains with the highest yield (Y-1091, Y-6987 and R4) under the assayed conditions (Table 1).

On other hand, RCL-11, Y-323, Y-17092 and Y-34 proved to be nonoleaginous since total lipid accumulation was less than $20 \% \mathrm{w} / \mathrm{w}$ of their dry biomass. These non-oleaginous yeasts could be used as negative controls in future evaluations of lipid production. Normally, $S$. cerevisiae is used as a negative control, but it would be more appropriate to use yeast controls belonging to the same genera.

Among Rhodotorula spp., R4, Y-1091, Y-6985, and Y-6987 strains reached the highest lipids accumulation, with an optimal growth, high lipid production and less residual glucose, which was reflected in yield coefficients and volumetric productivity (Table 1 ). Results demonstrated that $R$. glutinis $\mathrm{R} 4$ presents similar lipids accumulation (47 \%, w/ w) to Y-1091 (48.9\%) and Y-6987 (47\%), which are used as positive control of oleaginous yeasts (Table 1 ). In this sense, $R$. glutinis R4 showed a remarkable ability for lipid production $\left(\sim 7 \mathrm{~g} \mathrm{~L}^{-1} ; 47 \%\right)$ in GMY after $120 \mathrm{~h}$ of culture. In addition, growth parameters such as $\mu_{\max }$ and generation time of R4 were among the highest observed presenting a behavior similar to Y-1091, and higher than Y-6987 and Y-6985 (Table 2).

The highest values of biomass $\left(14-16 \mathrm{~g} \mathrm{~L}^{-1}\right)$, lipid production (6.8-7.3 $\mathrm{g} \mathrm{L}^{-1}$ ) and accumulation (43.9-48.9\%, w/w), yield coefficients $\left(\mathrm{Y}_{\mathrm{L} / \mathrm{S}}: 0.18-0.22 \mathrm{~g} \mathrm{~g}^{-1}, \mathrm{Y}_{\mathrm{L} / \mathrm{X}}: 0.45-0.50 \mathrm{~g} \mathrm{~g}^{-1}, \mathrm{Y}_{\mathrm{X} / \mathrm{S}}: 0.40-0.47 \mathrm{~g}\right.$ $\left.\mathrm{g}^{-1}\right)$ and volumetric productivity $\left(\mathrm{Q}_{\mathrm{L}}: 0.057-0.061 \mathrm{~g} \mathrm{~L}^{-1} \mathrm{~h}^{-1} ; \mathrm{Q}_{\mathrm{X}}\right.$ : 0.119-0.134 $\mathrm{g} \mathrm{L}^{-1} \mathrm{~h}^{-1}$ ) were reached by Y-1091, Y-6987, R4 and Y6985 (Table 1). On the other hand, $R$. toruloides Y-1588 had the lowest lipid production compared to the rest of the oleaginous yeasts.
Table 2

Parameters the growth and residual glucose by Rhodotorula spp. and Yarrowia spp. growth in GMY at $25^{\circ} \mathrm{C}$ during $120 \mathrm{~h}$.

\begin{tabular}{|c|c|c|c|}
\hline Strains & $\begin{array}{l}\mu \max \\
\left(\mathrm{h}^{-1}\right)\end{array}$ & $\begin{array}{l}\text { GT } \\
\text { (h) }\end{array}$ & $\begin{array}{l}\text { Res. glucose } \\
\left(\mathrm{g} \mathrm{L}^{-1}\right)\end{array}$ \\
\hline R. toruloides Y-1091 & $0.092 \pm 0.001^{\mathrm{bc}}$ & $3.3 \pm 0.05^{\mathrm{b}}$ & $4.53 \pm 0.23^{\mathrm{d}}$ \\
\hline R. toruloides Y-6987 & $0.070 \pm 0.001^{\mathrm{e}}$ & $4.3 \pm 0.09^{\mathrm{de}}$ & $6.37 \pm 0.62^{\mathrm{cd}}$ \\
\hline R. glutinis $R 4$ & $0.092 \pm 0.002^{\mathrm{bc}}$ & $3.3 \pm 0.05^{\mathrm{b}}$ & $6.84 \pm 1.19^{\mathrm{cd}}$ \\
\hline R. toruloides Y-6985 & $0.044 \pm 0.001^{\mathrm{h}}$ & $6.8 \pm 0.02^{g}$ & $3.89 \pm 0.61^{\mathrm{d}}$ \\
\hline R. toruloides Y-1588 & $0.063 \pm 0.005^{f}$ & $4.8 \pm 0.35^{\mathrm{e}}$ & $6.31 \pm 0.95^{\mathrm{cd}}$ \\
\hline R. mucilaginosa RCL11 & $0.115 \pm 0.002^{\mathrm{a}}$ & $2.6 \pm 0.05^{\mathrm{a}}$ & $12.73 \pm 1.56^{\mathrm{a}}$ \\
\hline Y. lipolytica Y-323 & $0.095 \pm 0.003^{b}$ & $3.2 \pm 0.09^{\mathrm{b}}$ & $12.23 \pm 0.99^{\mathrm{a}}$ \\
\hline R. toruloides Y-17092 & $0.088 \pm 0.001^{\mathrm{c}}$ & $3.4 \pm 0.01^{\mathrm{bc}}$ & $10.82 \pm 1.40^{\mathrm{ab}}$ \\
\hline R. glutinis Y-34 & $0.054 \pm 0.004^{g}$ & $5.6 \pm 0.46^{\mathrm{f}}$ & $7.06 \pm 0.84^{\mathrm{bcd}}$ \\
\hline
\end{tabular}

Data are the mean \pm standard deviation (St. D) of three independent experiments. The maximum specific growth rate ( $\mu$ max), generation time (GT) and residual glucose. Values followed by the same letters do not differ significantly, Tukey's test, $\alpha=0.05$.

The results allowed determining that the growth was supported by an initial YAN (Yeast Assimilable Nitrogen) of $150.9 \mathrm{mg} \mathrm{N} \mathrm{L}^{-1}$ and $40 \mathrm{~g}$ $\mathrm{L}^{-1}$ of glucose, creating a medium rich in glucose but poor in nitrogen. Several papers reported that oleaginous yeasts can accumulate neutral intracellular lipids when there is an excess of carbon and limitation of other nutrients, especially nitrogen (Donot et al., 2014). Our results showed that after $24 \mathrm{~h}$ the nitrogen was almost completely depleted (92-94 \%) while glucose was consumed less than $20 \%$ (Fig. 1). This limitation stimulates a cell growth decrease at some point in the exponential phase and then the yeast enters the stationary phase (Ratledge, 1991).

Despite the limitation of nitrogen, as shown in Fig. 1, the yeasts presented an increase in the OD and biomass values (Supplementary 1). When this unbalanced metabolism occurs, the oleaginous species can continue consuming the source of glucose (Fig. 1), which is converted into neutral lipids and stored as energy reserves. This can lead to an increase in cell size by the accumulation of lipids inside and to a lesser extent to cell duplication (Donot et al., 2014). Additionally, in oleaginous yeasts the intracellular concentration of $\mathrm{NH}_{4}{ }^{+}$rapidly increases 


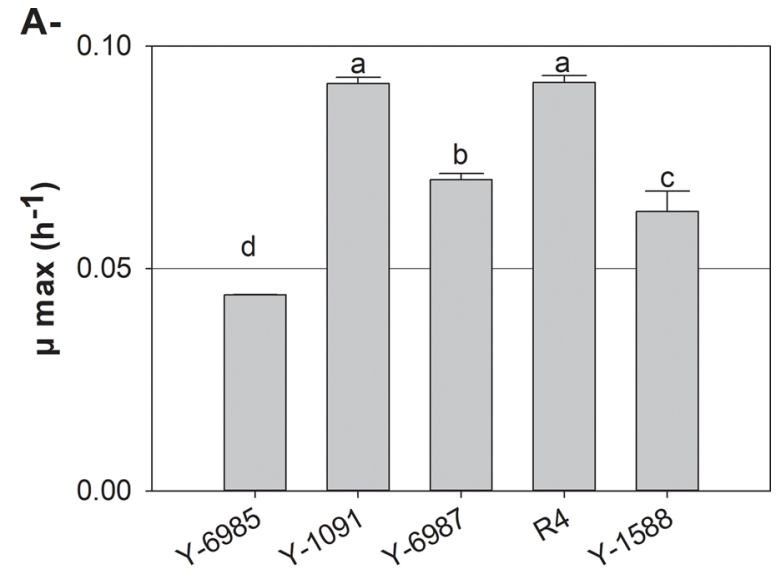

B-

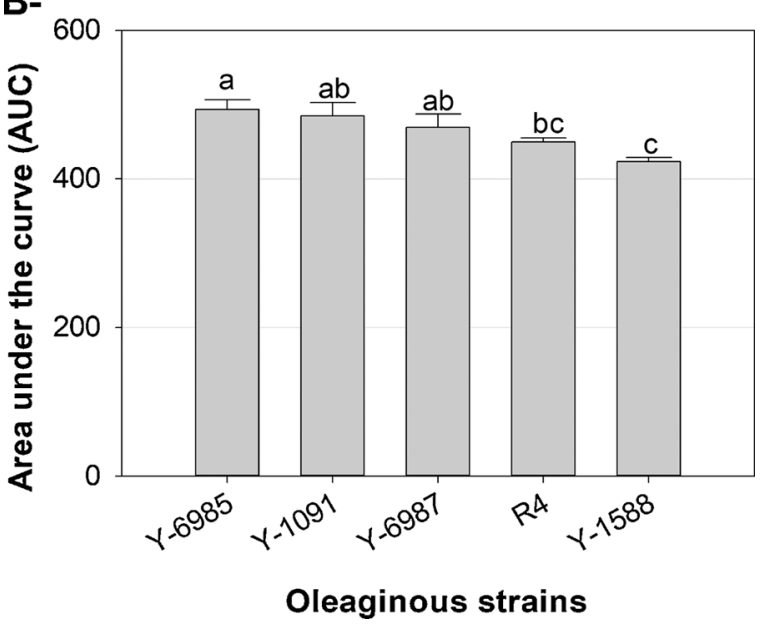

Fig. 2. Growth parameters. A- The mean area under the curve (AUC) of the different oleaginous yeasts are represented in the graph. The yeasts were grown in GMY medium for $120 \mathrm{~h}$ at $25^{\circ} \mathrm{C}$ with stirring. B- Then the growth rate in media for different cells was evaluated and represented the average of the maximum specific growth rate, $\mu$ max $\left(h^{-1}\right)$. Data are the mean \pm standard deviation (error bars) of three independent experiments. Values followed by the same letter are not statistically different $(\alpha \leq 0.05)$.

upon nitrogen exhaustion, the AMP is broken down into IMP (inosine-mono-phosphate) and $\mathrm{NH}_{4}{ }^{+}$by AMP-desaminase. The $\mathrm{NH}_{4}{ }^{+}$ ions constitute a temporary nitrogen source (Ratledge and Wynn, 2002). On the other hand, it is known $S$. cerevisiae continues growing after the nitrogen in the medium is completely consumed. Gutierrez et al., (Gutiérrez et al., 2016) demonstrated that the nitrogen uptake is decoupled from cell growth. The nitrogen is quickly assimilated from the culture medium and it is used to replenish intracellular nitrogen pools, rather than being channeled directly into cellular division. This reserve is used by these yeasts to continue their growth after nitrogen has been depleted (Ratledge and Wynn, 2002).

In all cases, the growth of the yeasts after $120 \mathrm{~h}$ evidenced the presence of residual glucose (4-5 \%) in GMY medium (Table 2, Fig. 1). Moreover, better glucose consumption (83-90\%) was observed for Y1091, Y-6985, Y-6987, R4 and Y-1588 compared to the rest of the evaluated yeasts. Meanwhile, the nitrogen was consumed almost completely (95-97\%) after $24 \mathrm{~h}$ and then remained constant for $120 \mathrm{~h}$ for all the yeasts evaluated (Fig. 1).

When the general growth was studied in more detail in the oleaginous yeasts as area under the curve (AUC), R4, Y-6987 and Y1091 presented similar growth (AUC) in the evaluated conditions (Fig. 2A). However, significant differences were observed between them when the maximum specific growth rates $\left(\mu_{\max }\right)$ were compared (Fig. 2B). The $\mu_{\max }$ of Y-1091 and R4 were the highest $\left(0.092 \mathrm{~h}^{-1}\right)$ while Y-6987 showed a lower value $\left(\mu_{\max }=0.070 \mathrm{~h}^{-1}\right)$. On the other hand, although Y-6985 had an AUC value greater than all oleaginous yeasts (Fig. 2A), R4 presented a specific growth rate $\left(0.092 \mathrm{~h}^{-1}\right)$ greater than Y-6985 $\left(0.044 \mathrm{~h}^{-1}\right)$ (Fig. 2B). The rapid growth and high biomass production by $R$. glutinis $\mathrm{R} 4$ would be an advantage over other yeast during larger scale production of yeast-based biodiesel since it would allow for shorter batch times and increased lipid accumulation.

This study allowed us to demonstrate that lipids production and accumulation of $R$. glutinis R4 isolated from Antarctica exhibited similar values to $R$. toruloides Y-1091, $R$. toruloides Y-6987 and other oleaginous yeasts reported in the literature (Amaretti et al., 2010; Li et al., 2007; Viñarta et al., 2016). In addition, lipids parameters, yield coefficients and volumetric productivity are high and show that R4 is a strain with high potential for lipid production. Meanwhile, under the same conditions, $R$. glutinis Y-34, R. mucilaginosa RCL11, R. toruloides Y-17092 and $Y$. lipolytica $\mathrm{Y}-323$ proved not to be oleaginous yeasts.

In addition, $R$. glutinis $\mathrm{R} 4$ is a psychrotolerant yeast. Among the advantages of the cold-adapted yeasts for SCO production, it is important to mention that they are excellent lipids-producers and they have a fatty acids composition rich in unsaturated fatty acids containing a high content of monounsaturated fatty acids (MUFA), mainly rich in oleic acid (C18:1) and may be used as more suitable feedstock for biodiesel production operating in winter conditions (Rossi et al., 2009; Taskin et al., 2015).

\subsection{Analysis of lipid bodies by Nile Red staining under fluorescence microscopy}

In order to observe the neutral lipids and to confirm the presence of lipid bodies, yeasts were stained with Nile Red, which is used as an "in situ" marker of TAG. In this assay, the Nile Red marker shows a high yellow-gold fluorescence in hydrophobic environments at an excitation wavelength of $515-560 \mathrm{~nm}$ and a $>590 \mathrm{~nm}$ emission. Yeasts were cultured in GMY medium for $120 \mathrm{~h}$ at $25^{\circ} \mathrm{C}$, stained with Nile Red and observed by fluorescent microscopy. $S$. cerevisiae was used as a negative control and R. toruloides Y-1091 as positive control (Fig. 3). All oleaginous yeasts showed a yellow-gold emission with different intensities. All Rhodotorula strains showed lipid bodies, but differences were observed in the size, shape, intensity and persistence of the emission of fluorescence, which demonstrated that all of them accumulate neutral intracellular lipids. In S. cerevisiae ATCC 32051 these features were not observed even when it was cultured under the same conditions and culture time Fig. 3). Similar results were reported by Viñarta et al. (2016) for a qualitative selection by fluorescence microscopy with Nile Red staining of oleaginous yeasts isolated from Antarctica (Viñarta et al., 2016).

Nile Red staining was used by several authors to observe lipid bodies in oleaginous yeasts (Kimura et al., 2004; Sitepu et al., 2013; Viñarta et al., 2016). The Nile Red molecule allows a rapid evaluation of lipids accumulation, but it may non-specifically bind to certain nonlipid cellular compartments containing a hydrophobic region (Rumin et al., 2015), so it was necessary to quantify the intracellular lipids content.

\subsection{Determination of TAG by thin layer chromatography (TLC)}

Lipids were analyzed by thin layer chromatography (TLC), and olive oil was used as a reference of vegetable oil. Results demonstrated that 


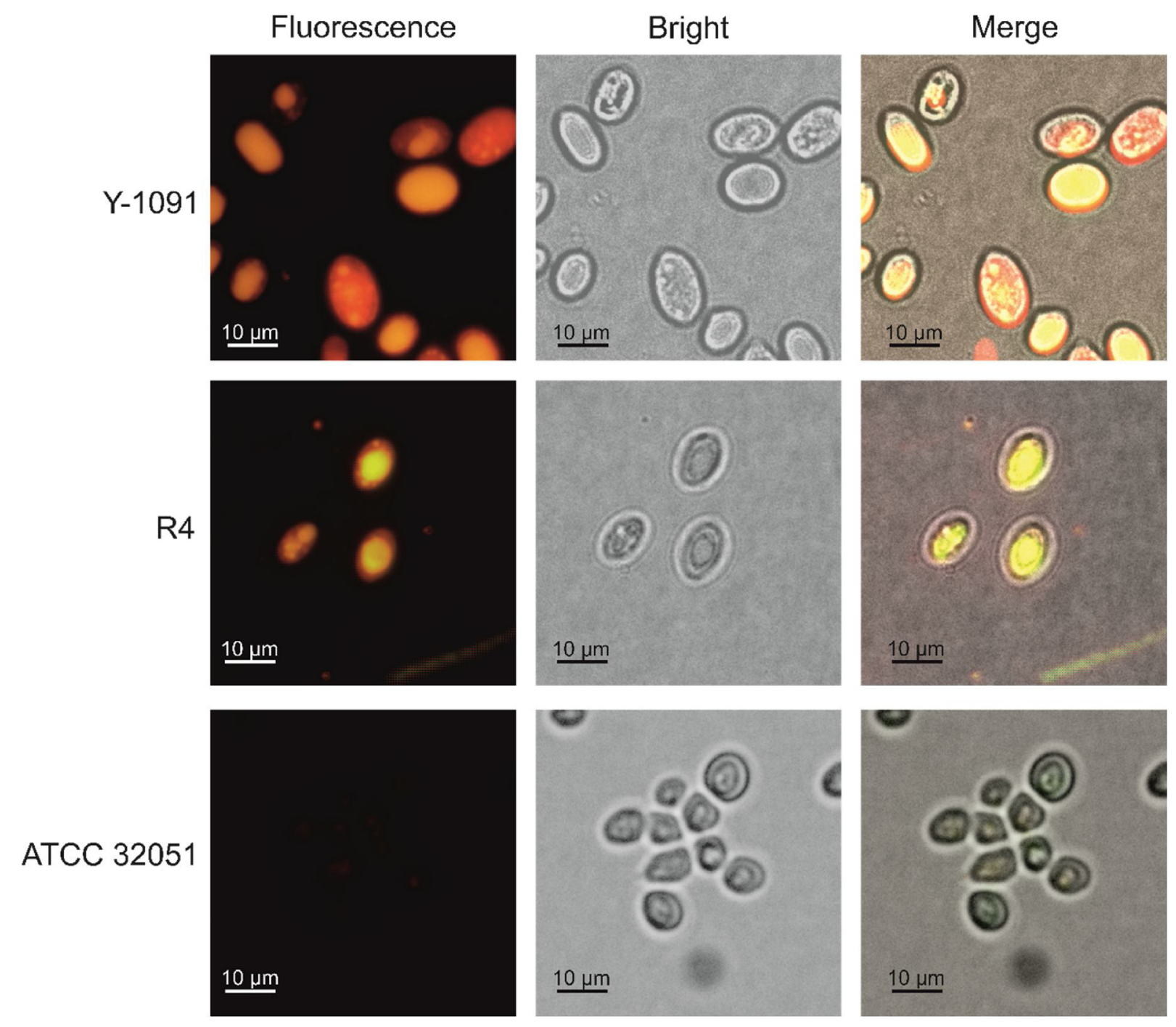

Fig. 3. Microscopy of oleaginous yeasts. Micrographs show fluorescent lipid droplets of R. glutinis Y-1091 (positive control); R. glutinis R4 and S. cerevisiae ATCC 32051 (negative control). The image shows the same cells under epifluorescence microscopy, bright field, and the merge of both images; bars represent $10 \mu \mathrm{m}$. Yeasts were cultured in GMY medium for $120 \mathrm{~h}$ and then stained by incubation with Nile Red. Magnification used for micrographs was $100 \times$.

R4, Y-1091, Y-6987 and Y-6985 have TAG and other components with a profile similar to vegetable oils under the assayed culture conditions (Fig. 4). These results suggest that the oleaginous yeast $R$. glutinis R4 analyzed in this study can be considered as an alternative source of triglycerides for biotechnological applications.

\subsection{Analysis of fatty acids profiles}

Determination of the FAME profile of oils is essential, as it composition affects the biodiesel quality. The abundance of fatty acids (FA) of microbial TAG synthetized by $R$. glutinis $\mathrm{R} 4$ was assessed. Long-chain fatty acids (C14-C18) were detected in the FAME profile of the lipids produced by $R$. glutinis R4 (Table 3). The FA profile of R4 contains mainly C16 and C18 FA, including their saturated, monounsaturated, and poly-unsaturated forms, which represent 96-97\% of the total (Table 3), in concordance with vegetable oils and single cell oils (SCO) from oleaginous yeasts. Several authors indicated that oleaginous yeasts produce microbial oils with a similar composition to plant oils containing predominantly saturated (SFA) or monounsaturated (MUFA) fatty acids with 16 and 18 carbon chain length (Beopoulos et al., 2009; Li et al., 2008; Meng et al., 2009; Papanikolaou and Aggelis, 2011).

On the other hand, FA with a chain length of 18 carbons (78-79\%) were the most abundant (Table 3). Production of C18 FA was previously described as an adaptive feature of yeasts from cold environments. This adaptation may be associated with the necessity to elongate FA beyond C16 to introduce additional double bonds by $\Delta 12$ and $\Delta 15$ desaturases (Rossi et al., 2009).

The most abundant FA, in descending order, were oleic (C18:1, n-9), palmitic (C16:0) and linoleic (C18:2, n-6) acids with percentages ranging from $\sim 58-62 \%, \sim 17 \%$ and $\sim 12-13 \%$ of total FA, respectively (Table 3). The FA profile observed for R4 containing oleic, linoleic and palmitic acids as main fatty acids agrees with the composition typically reported for SCO produced by strains of $R$. glutinis (Saenge et al., 2011a,b) and other oleaginous yeasts (Amaretti et al., 2010; Papanikolaou and Aggelis, 2011; Subramaniam et al., 2010). Additionally, it has been reported that this FA abundance can differ between species (Beopoulos et al., 2009; Li et al., 2008; Meng et al., 2009). Fatty acids speciation data exhibited by $R$. glutinis $R 4$ agrees with previously reported values of C16:0, C18:1 and C18:2, C18:1 being the main species present in oleaginous yeasts (Amaretti et al., 2010; Deeba et al., 2018; El-Fadaly et al., 2009; Enshaeieh et al., 2014).

On the other hand, no significant differences were observed in FA profile of SCO from R4 obtained after 120 and $144 \mathrm{~h}$ of culture (Table 3). Only minimal differences were found in the content of saturated fatty acids (SFA), monounsaturated fatty acids (MUFA) and polyunsaturated fatty acids (PUFA). In addition, the content of linolenic 


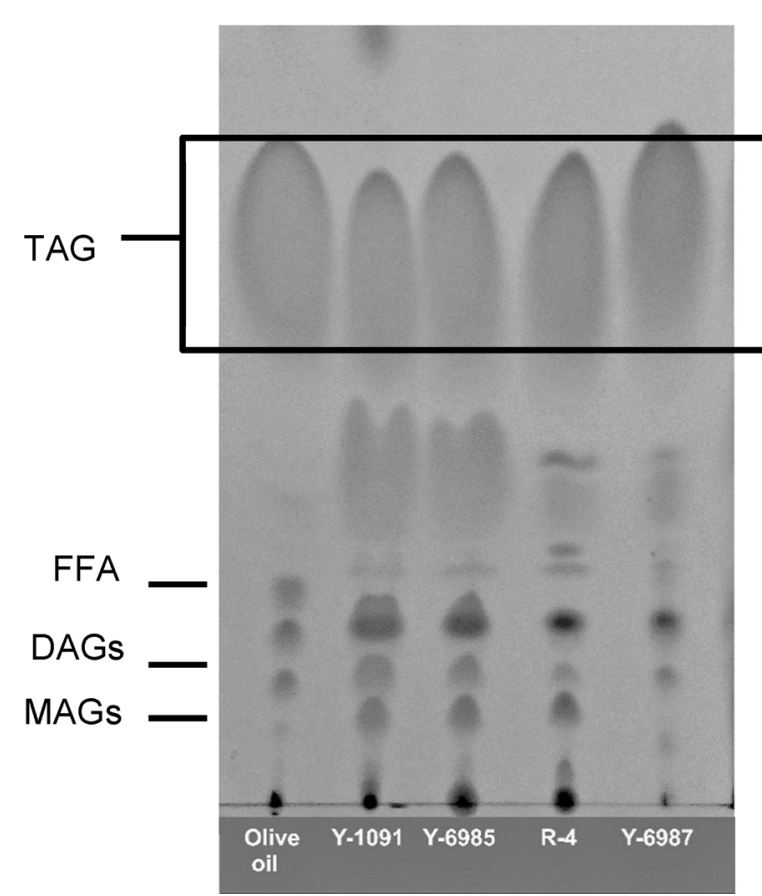

Fig. 4. TLC analysis of lipids present in oil extracts of yeasts Y-1091 and R4, and olive oil. Yeasts were grown in GMY medium after $120 \mathrm{~h}$ of culture time. Lipid extracts from yeast strains were resolved using a solvent system to separate TAG from other lipid species (see Materials and methods). TAG present in olive oils standards were used to identify the Rf value for TAG from yeasts under the chromatographic conditions used. Lipids production and accumulation are comparable with other oleaginous yeasts reported in the literature (Amaretti et al., 2010; Viñarta et al., 2016). TAG, Triacylglycerides; DAG Diacylglycerides, FFA; free fatty acids, and MAG, Monoacylglycerides.

acid (C18:3) did not show significant differences in time and was less than $12 \%$ as required by international biodiesel standards.

In general, FA composition of SCO by R. glutinis R4 agrees with the FA profile of Rhodotorula spp. and of vegetable oils (Table 3 ). Also, the high content of oleic and palmitic acids observed here for R. glutinis R4 is propitious for biodiesel synthesis (Amaretti et al., 2010; El-Fadaly et al., 2009; Enshaeieh et al., 2014; Li et al., 2008).

Content of unsaturated fatty acids (UFA) in R. glutinis R4 was predominant over saturated fatty acids, SFA (20-22\%) (Table 3), which is in agreement with previous reports for oleaginous yeasts species (Amaretti et al., 2010; Subramaniam et al., 2010). An optimum ratio of SFA and UFA is necessary for better physical properties of biodiesel generation with good physical parameters (Knothe, 2006; Ramos et al., 2009). Contents of PUFA and SFA in FAME of SCO yielded by $R$. glutinis R4 are suitable for biodiesel. All these characteristics are very important because to the FAME composition affects biodiesel quality. FA from $R$. glutinis R4 are suitable for biodiesel synthesis and were produced in appreciable amounts. Taken together, our results demonstrate that $R$. glutinis $\mathrm{R} 4$ could be a promising feedstock for third-generation biodiesel.

\subsection{Biodiesel properties}

To assess the acceptability and quality of biodiesels produced by $R$. glutinis R4, the main physicochemical fuel properties were estimated through empirical formulas using FA profiles. Estimated properties were compared with ASTM D6751 and EN 14214 standards ASTM, 2019; CEN, 2009) as well as commercially used vegetable oil methyl esters (palm, rapeseed, olive) and the estimated parameters for biodiesel from other oleaginous yeasts. Results indicated that biodiesels derived from R4 satisfied the limits imposed by international fuel

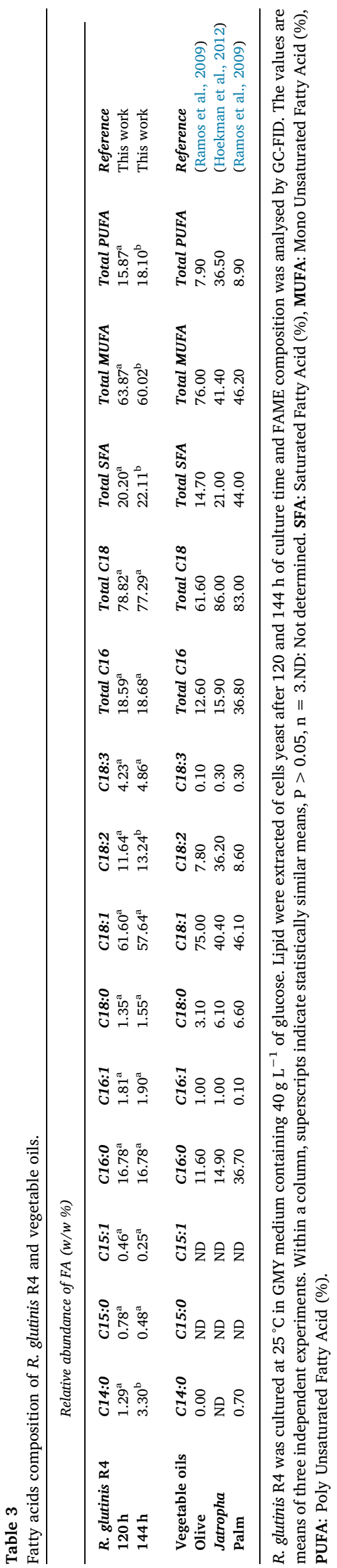


Table 4

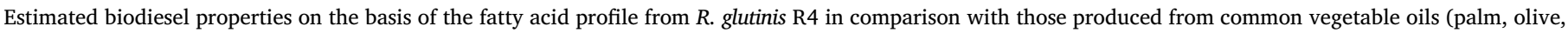
rapeseed) and oleaginous yeasts, tested according to ASTM D6751 and EN 14214 international biodiesel standards.

Biodiesel sources

\begin{tabular}{|c|c|c|c|c|c|c|c|c|c|c|}
\hline \multirow[b]{2}{*}{ Biodiesel properties } & \multirow[b]{2}{*}{ ASTM D6751 } & \multirow[b]{2}{*}{ EN 14214} & \multicolumn{2}{|c|}{ Rhodotorula glutinis R4 } & \multicolumn{3}{|c|}{ Vegetable oils } & \multicolumn{3}{|c|}{ Oleaginous yeasts } \\
\hline & & & $120 \mathrm{~h}$ & $144 \mathrm{~h}$ & Palm & Olive & Rapeseed & Y. lipolytica & R. toruloides & R. glutinis \\
\hline SV (mg KOH) & NS & NS & 203.29 & 203.57 & ND & ND & $\mathrm{ND}$ & 197.50 & 204.70 & 197.12 \\
\hline IV $\left(\mathrm{gI}_{2} / 100 \mathrm{~g}\right)$ & NS & $\leq 120$ & 89.92 & 91.01 & 57.00 & 84.00 & 109.00 & 76.40 & 61.40 & 99.86 \\
\hline $\mathrm{CN}$ & $\geq 47$ & $\geq 51$ & 52.92 & 52.63 & 61.00 & 57.00 & 55.00 & 56.70 & 59.20 & 48.52 \\
\hline OS (h) & NS & $\geq 6$ & 10.02 & 9.11 & 4.00 & 3.30 & 2.00 & ND & ND & 7.04 \\
\hline DU (\% wt) & NS & NS & 95.21 & 95.74 & 64.20 & 92.70 & 121.90 & ND & ND & 109.45 \\
\hline LCSF (wt \%) & NS & NS & 2.61 & 2.45 & 7.70 & 4.20 & 1.30 & 6.80 & 10.40 & 3.88 \\
\hline CFPP $\left({ }^{\circ} \mathrm{C}\right)$ & NS & +5 to -20 & -8.27 & -8.77 & 10.00 & -6.00 & -10.00 & 4.90 & 16.20 & -3.21 \\
\hline HHV MJ/Kg & NS & $\sim 35$ & 39.49 & 39.34 & NS & NS & NS & ND & ND & 39.85 \\
\hline$\nu\left(\mathrm{mm}^{2} \mathrm{~s}^{-1}\right)$ & $1.9-6$ & $3.5-5$ & 3.85 & 3.78 & 4.50 & 4.50 & 4.40 & ND & ND & 3.96 \\
\hline$\rho\left(\mathrm{g} / \mathrm{cm}^{3}\right)$ & NS & $0.86-0.90$ & 0.87 & 0.87 & NS & NS & NS & ND & ND & 0.88 \\
\hline C18:3 (\%) & NS & $\leq 12$ & 4.23 & 4.86 & 0.20 & 0.60 & 7.90 & 0.00 & 2.60 & 6.30 \\
\hline \multicolumn{3}{|l|}{ References } & This work & This work & \multicolumn{3}{|c|}{ (Ramos et al., 2009) } & \multicolumn{2}{|c|}{ (Munch et al., 2015) } & (Patel et al., 2016) \\
\hline
\end{tabular}

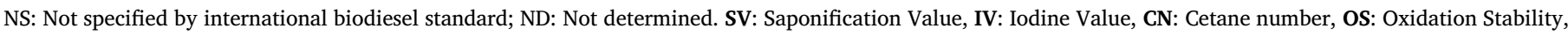

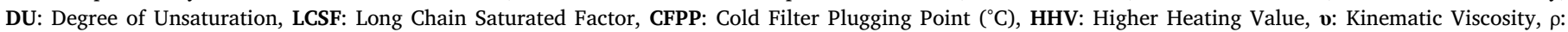
Density, C18:3, Linolenic acid content.

standards for critical quality parameters (Table 4). In addition, the physicochemical properties were also comparable with biodiesel from vegetable oils and oleaginous yeasts as $Y$. lipolytica, $R$. toruloides, $C$. vishniaccii, $R$. mucilaginosa and $R$. glutinis.

Among physicochemical properties, cetane number $(\mathrm{CN})$, iodine value (IV), oxidation stability (OS), and cold filter plugging property (CFPP) have been identified as the main parameters of biodiesel quality. These properties are greatly affected by the unsaturation and saturation degree, accordingly, the FA composition of the feedstock strongly influences biodiesel quality. Consequently, both unsaturation and saturation of FAME must be optimum to enhance biodiesel quality (Ramos et al., 2009).

Biodiesel of the Antarctic yeast R. glutinis R4 exhibited good fuel properties and satisfied the limits imposed by international fuel standards for critical quality parameters (Table 4). In addition, the physicochemical properties of the biodiesels from $R$. glutinis R4 were also comparable with biodiesel from the vegetable oils and from oleaginous yeasts such as Yarrowia lipolytica, Rhodosporidium toruloides and Rhodotorula glutinis (Table 4).

High CN ensures efficient engine performance because it guarantees better combustion and lesser emissions of pollutant (Knothe, 2006). The CN for biodiesel should be a minimum of 47 ASTM D6751 or 51 EN 14214. Accordingly, $\mathrm{CN}$ for biodiesels from $R$. glutinis R4 $(\mathrm{CN}=52.63-53.05)$ met the biodiesel standard defined by ASTM D6751 and EN 14214 Table 4). CN is greatly influenced by unsaturation degree (DU) and it has been demonstrated that $\mathrm{CN}$ decreases with increasing unsaturation of FA (Knothe, 2006; Ramos et al., 2009). IV is related to the oxidation stability of the fuel and it is affected by the unsaturation degree (Knothe, 2006. The limit established for IV by EN 14214 is $\leq 120 \mathrm{~g} \mathrm{I}_{2} / 100 \mathrm{~g}$ ). IV values determined for biodiesels derived from R4 was adequate (IV $=89.92$ and $91.01 \mathrm{I}_{2} / 100 \mathrm{~g}$ and did not exceed the limit established by EN 14214 specifications.

The parameters of biodiesel to satisfy the vehicular quality include kinematic viscosity ( $\nu$ ), density ( $\rho$ ) and $\mathrm{CN}$. CN importance was discussed above. Kinematic viscosity and density viscosity are correlated with the degree of unsaturation and saturation, respectively (Patel et al., 2016). Kinematic viscosity is the resistance of liquid to flow and depends on the thickness of the oil. An appropriate $v$ in a biodiesel ensures adequate fuel supply at different operating temperatures (Ramírez-Verduzco et al., 2012). Kinematic viscosity estimated from biodiesel from R4 $\left(3.8 \mathrm{~mm}^{2} / \mathrm{s}\right)$ met the range established by EN14214 $\left(3.5-5 \mathrm{~mm}^{2} / \mathrm{s}\right)$.

Density affects the net energy content of the fuel (Patel et al., 2016).
Predicted $\rho$ value was also adequate (Table 4). Calculated CN (52.63-53.05), $\nu\left(3.8 \mathrm{~mm}^{2} / \mathrm{s}\right)$, and $\rho\left(\sim 0.87 \mathrm{~g} / \mathrm{cm}^{3}\right)$ of $\mathrm{R} 4$ satisfied both European and American standards (Table 4). The CFPP is a parameter used for the prediction of biodiesel behavior at low temperatures, although, this parameter varies with country and season. European standard suggests a range between $+5{ }^{\circ} \mathrm{C}$ and $-20{ }^{\circ} \mathrm{C}$. In this work, the estimated CFPP for $\mathrm{R} 4$ ranged between $-8.8^{\circ} \mathrm{C}$ and $-9{ }^{\circ} \mathrm{C}$, matching the standards and demonstrating the potential for good performance at low-temperatures of the biodiesels derived by $R$. glutinis R4 (Table 4). Patel et al. (2016) estimated a CFPP of $-3.21^{\circ} \mathrm{C}$ for an $R$. glutinis strain. $\mathrm{HHV}$ is the heat produced after complete combustion (Patel et al., 2016). Biodiesel produced from vegetable oil has lower HHV than diesel derived from petroleum. However, for R. glutinis R4 from Antarctica, predicted HHV (39.3-39.5 MJ/Kg) was similar to petrodiesel $(39-41 \mathrm{MJ} / \mathrm{Kg})$. According to the results, estimated values of IV ( $90-91 \mathrm{~g} \mathrm{I}_{2} / 100 \mathrm{~g}$ and $\mathrm{CN} \sim 53$ were suitable and fit in the limits imposed by international biodiesel standard specifications EN 14214: $\mathrm{CN}=51 \mathrm{~min}$; IV: $120 \mathrm{~g} \mathrm{I} / 100 \mathrm{~g}$ max; ASTM D6751: $\mathrm{CN}=49 \mathrm{~min}$. Biodiesels derived from $R$. glutinis R4 from Antarctica has good estimated CN, IV and OS values, as well as an appropriated unsaturation degree. Besides, the biodiesel from the Antarctic yeast, R4 strain, studied in this work has less than $12 \%$ of C18:3 content in their FAME profile as required by EN 14214 standard.

As shown in Table 4, the main quality parameters of biodiesel from R4 were comparable to the biodiesel produced from rapeseed, palm and olive oils. Ramos et al. (2009) have indicated that biodiesel of these vegetable oils have better properties for fuel uses. In Europe, rapeseed oil is the preferred biodiesel feedstock, whereas in tropical countries palm oil is more common. In addition, oxidation stability (OS) values $(9-10 \mathrm{~h})$ exhibited by biodiesel from R4 were higher than those estimated for vegetable oil methyl esters $(2-4 \mathrm{~h})$. These results indicate the excellent quality of the biodiesels produced by $R$. glutinis R4, as well as the potential of this yeast as a source of oils for biodiesel production. Parameters were also comparable with estimated values reported for biodiesels derived by other oleaginous yeasts such as $R$. glutinis, $R$. toruloides and Yarrowia lipolytica (Munch et al., 2015; Patel et al., 2016) (Dasgupta et al., 2017; Furthermore, OS estimated for R. glutinis R4 (OS $\sim 10 \mathrm{~h}$ ) was higher than the OS reported by Patel et al. (2016) for other strain of $R$. glutinis ( $\mathrm{OS}=7 \mathrm{~h}$ ) as shown in Table 4. According to our results, it is possible to speculate that the high CN (53), longer OS (10 h) and low CFPP (R15: $-9{ }^{\circ} \mathrm{C}$ ) obtained ensures efficient engine performance, reduced emissions, better performance at low temperatures, better stability to oxidation and longer shelf life. In addition, the OS and 
CFPP were better than rapeseed, olive and palm methyl esters. Altogether, our results demonstrate that $R$. glutinis $\mathrm{R} 4$ could be considered as a promising feedstock for biodiesel synthesis.

\section{Conclusion}

This work comparatively evaluated the ability for lipid production of nine yeast strains. $R$. glutinis R4, R. toruloides Y-1091 and R. toruloides Y-6987 exhibited the best growth and lipid synthesis parameters. In addition, this work demonstrates for the first time that Y-6985 is an oleaginous yeast.

Among Rhodotorula spp., $R$. glutinis R4 showed a remarkable ability for lipid production with good growth and efficient glucose consumption. In addition, growth parameters, yield coefficients and lipid volumetric productivity demonstrated that $R$. glutinis $\mathrm{R} 4$ is a yeast with high potential as a lipid producer.

Microbial oils produced by $R$. glutinis R4 are similar to vegetable oils containing mainly FA with 16 and 18 carbon atoms, including saturated, monounsaturated and poly-unsaturated forms. Oleic (C18:1), palmitic (C16:0) and linoleic (C18:2) acids were the most abundant FA in SCO of $R$. glutinis R4. The high content of C18:1 and C16:0 acids produced by $R$. glutinis $\mathrm{R} 4$ is propitious for biodiesel synthesis. In addition, the content of linolenic acid (C18:3) was less than $12 \%$ as required by international biodiesel standards. Results indicated that biodiesel from $R$. glutinis R4 exhibited good fuel properties as shown in the main quality parameters. In addition, data indicated that biodiesels derived from $R$. glutinis R4 satisfied the limits imposed by international fuel standards ASTM D6751 and EN 14214.

As a final conclusion, FA from $R$. glutinis R4 are suitable for biodiesel synthesis and were produced in appreciable amounts. Taken together, our results prove that $R$. glutinis R4 could be proposed as a promising feedstock for third-generation biodiesel.

\section{Funding information}

This work was supported by the Agencia Nacional de Promoción Científica y Tecnológica, FONCYT (PICT2013-1154; PICT2016-3083; PICT2013-2016, РICT2013-1686, PICT2015-1207, РICT2018-1370); Consejo Nacional de Investigaciones Científicas y Técnicas CONICET (PUE-2016-0012, PIP0677-2015) and the Secretaría de Ciencia, Arte e Innovación Tecnológica de la Universidad Nacional de Tucumán, SCAIT-UNT, (PIUNT D509 and PIUNT D605).

\section{CRediT authorship contribution statement}

D. Daniela Maza: Investigation, Formal analysis, Validation, Visualization, Writing - original draft. Silvana C. Viñarta: Investigation, Data curation, Methodology, Conceptualization, Supervision, Funding acquisition, Writing - original draft, Writing review \& editing. Ying Su: Investigation, Validation. José Manuel Guillamón: Methodology, Funding acquisition, Supervision, Writing review \& editing. Manuel J. Aybar: Methodology, Visualization, Funding acquisition, Resources, Supervision, Writing - original draft, Writing - review \& editing.

\section{Declaration of Competing Interest}

The authors declare that they have no conflict of interests.

\section{Acknowledgements}

The authors would like to thank specially to Dirección Nacional del Antártico (DNA) and Instituto Antártico Argentino (IAA) for supporting the Antarctic expeditions where the samples were collected under an agreement with Dr. Walter Mac Cormack and the Environmental Microbiology Group. We are grateful to Mr. Antonio Lopez Ruiz for technical assistance in HPLC techniques, and to Mrs. Virginia Méndez for her proofreading.

\section{Appendix A. Supplementary data}

Supplementary material related to this article can be found, in the online version, at doi:https://doi.org/10.1016/j.jbiotec.2020.01.012.

\section{References}

Alvarez, A.F., Alvarez, H.M., Kalscheuer, R., Wältermann, M., Steinbüchel, A., 2008. Cloning and characterization of a gene involved in triacylglycerol biosynthesis and identification of additional homologous genes in the oleaginous bacterium Rhodococcus opacus PD630. Microbiology 154, 2327-2335.

Amaretti, A., Raimondi, S., Sala, M., Roncaglia, L., De Lucia, M., Leonardi, A., Rossi, M. 2010. Single cell oils of the cold-adapted oleaginous yeast Rhodotorula glacialis DBVPG 4785. Microb. Cell Fact. 9, 73.

ASTM, 2019. ASTM D6751-11b, Standard Specification for Biodiesel Fuel Blend Stock (B100) for Middle Distillate Fuels. ASTM International West Conshohocken, PA.

Beopoulos, A., Nicaud, J.-M., 2012. Yeast: a new oil producer? Oléagineux, Corps gras. Lipides 19, 22-28.

Beopoulos, A., Cescut, J., Haddouche, R., Uribelarrea, J.-L., Molina-Jouve, C., Nicaud, J. M., 2009. Yarrowia lipolytica as a model for bio-oil production. Prog. Lipid Res. 48, 375-387.

Bligh, E.G., Dyer, W.J., 1959. A rapid method of total lipid extraction and purification. Can. J. Biochem. Physiol. 37, 911-917.

CEN, 2009. EN 14214 Automotive Fuels Diesel-Fatty Acid Methyl Esters (FAME)-Requirements and Test Methods. CEN Brussels, Belgium.

Deeba, F., Patel, A., Arora, N., Pruthi, V., Pruthi, P.A., Negi, Y.S., 2018. Amaranth seeds (Amaranthus palmeri L.) as novel feedstock for biodiesel production by oleaginous yeast. Environ. Sci. Pollut. Res. - Int. 25, 353-362.

Donot, F., Fontana, A., Baccou, J., Strub, C., Schorr-Galindo, S., 2014. Single cell oils (SCOs) from oleaginous yeasts and moulds: production and genetics. Biomass Bioenergy 68, 135-150.

El-Fadaly, H., El-Ahmady, N., Marvan, E., 2009. Single cell oil production by an oleaginous yeast strain in a low cost cultivation medium. Res. J. Microbiol. 4, 301-313.

Elshout, P.M., van Zelm, R., van der Velde, M., Steinmann, Z., Huijbregts, M.A., 2019. Global relative species loss due to first-generation biofuel production for the transport sector. GCB Bioenergy 11, 763-772.

Enshaeieh, M., Nahvi, I., Madani, M., 2014. Improving microbial oil production with standard and native oleaginous yeasts by using Taguchi design. Int. J. Environ. Sci. Technol. 11, 597-604.

Gómez-Alonso, S., Hermosín-Gutiérrez, I., García-Romero, E., 2007. Simultaneous HPLC analysis of biogenic amines, amino acids, and ammonium ion as aminoenone derivatives in wine and beer samples. J. Agric. Food Chem. 55, 608-613.

Gutiérrez, A., Sancho, M., Beltran, G., Guillamon, J.M., Warringer, J., 2016. Replenishment and mobilization of intracellular nitrogen pools decouples wine yeast nitrogen uptake from growth. Appl. Microbiol. Biotechnol. 100, 3255-3265.

Hoekman, S.K., Broch, A., Robbins, C., Ceniceros, E., Natarajan, M., 2012. Review of biodiesel composition, properties, and specifications. Renew. Sustain. Energy Rev. 16, 143-169. https://doi.org/10.1016/j.rser.2011.07.143.

Kimura, K., Yamaoka, M., Kamisaka, Y., 2004. Rapid estimation of lipids in oleaginous fungi and yeasts using Nile red fluorescence. J. Microbiol. Methods 56, 331-338.

Knothe, G., 2006. Analyzing biodiesel: standards and other methods. J. Am. Oil Chem. Soc. $83,823-833$.

Kurtzman, C., Fell, J.W., Boekhout, T., 2011. The Yeasts: a Taxonomic Study. Elsevier.

Li, Y., Zhao, Z., Bai, F., 2007. High-density cultivation of oleaginous yeast Rhodosporidium toruloides Y4 in fed-batch culture. Enzyme Microb. Technol. 41, 312-317.

Li, Q., du, W., Liu, D., 2008. Perspectives of microbial oils for biodiesel production. Appl. Microbiol. Biotechnol. 80, 749-756.

Liang, M.-H., Jiang, J.-G., 2013. Advancing oleaginous microorganisms to produce lipid via metabolic engineering technology. Prog. Lipid Res. 52, 395-408.

Lyman, M., Urbin, S., Strout, C., Rubinfeld, B., 2019. The Oleaginous Red Yeast Rhodotorula/Rhodosporidium: A Factory for Industrial Bioproducts.

Meng, X., Yang, J., Xu, X., Zhang, L., Nie, Q., Xian, M., 2009. Biodiesel production from oleaginous microorganisms. Renew. Energy 34, 1-5.

Munch, G., Sestric, R., Sparling, R., Levin, D., Cicek, N., 2015. Lipid production in the under-characterized oleaginous yeasts, Rhodosporidium babjevae and Rhodosporidium diobovatum, from biodiesel-derived waste glycerol. Bioresour. Technol. 185C, 49-55.

Osorio-González, C.S., Hegde, K., Ferreira, P., Brar, S.K., Kermanshahipour, A., Soccol, C.R., Avalos-Ramírez, A., 2019. Lipid production in Rhodosporidium toruloides using C-6 and C-5 wood hydrolysate: a comparative study. Biomass Bioenergy 130, 105355.

Papanikolaou, S., Aggelis, G., 2011. Lipids of oleaginous yeasts. Part I: biochemistry of single cell oil production. Eur. J. Lipid Sci. Technol. 113, 1031-1051.

Park, Y.-K., Nicaud, J.-M., Ledesma-Amaro, R., 2017. The engineering potential of Rhodosporidium toruloides as a workhorse for biotechnological applications. Trends Biotechnol. 36.

Patel, A., Arora, N., Sartaj, K., Pruthi, V., Pruthi, P.A., 2016. Sustainable biodiesel production from oleaginous yeasts utilizing hydrolysates of various non-edible lignocellulosic biomasses. Renew. Sustain. Energy Rev. 62, 836-855.

Ramírez-Verduzco, L.F., Rodríguez-Rodríguez, J.E., Jaramillo-Jacob, Ad.R., 2012. 
Predicting cetane number, kinematic viscosity, density and higher heating value of biodiesel from its fatty acid methyl ester composition. Fuel 91, 102-111.

Ramos, M.J., Fernández, C.M., Casas, A., Rodríguez, L., Pérez, Á., 2009. Influence of fatty acid composition of raw materials on biodiesel properties. Bioresour. Technol. 100, 261-268.

Ratledge, C., 1991. Microorganisms for lipids. Acta Biotechnol. 11, 429-438.

Ratledge, C., Wynn, J., 2002. The biochemistry and molecular biology of lipid accumulation in oleaginous microorganisms. Adv. Appl. Microbiol. 51, 1-51.

Rossi, M., Buzzini, P., Cordisco, L., Amaretti, A., Sala, M., Raimondi, S., Ponzoni, C., Pagnoni, U.M., Matteuzzi, D., 2009. Growth, lipid accumulation, and fatty acid composition in obligate psychrophilic, facultative psychrophilic, and mesophilic yeasts. FEMS Microbiol. Ecol. 69, 363-372.

Rovati, J., Pajot, H., Ruberto, L., Mac Cormack, W., Castellanos de Figueroa, L., 2013. Polyphenolic substrates and dyes degradation by yeasts from 25 de Mayo/King George Island (Antarctica). Yeast (Chichester, England) 30, 459-470.

Rumin, J., Bonnefond, H., Saint-Jean, B., Rouxel, C., Sciandra, A., Bernard, O., Cadoret, J.-P., Bougaran, G., 2015. The use of fluorescent Nile red and BODIPY for lipid measurement in microalgae. Biotechnol. Biofuels 8, 42.

Saenge, C., Cheirsilp, B., Suksaroge, T.T., Bourtoom, T., 2011a. Efficient concomitant production of lipids and carotenoids by oleaginous red yeast Rhodotorula glutinis cultured in palm oil mill effluent and application of lipids for biodiesel production. Biotechnol. Bioprocess Eng. 16, 23-33.

Saenge, C., Cheirsilp, B., Suksaroge, T.T., Bourtoom, T., 2011b. Potential use of oleaginous red yeast Rhodotorula glutinis for the bioconversion of crude glycerol from biodiesel plant to lipids and carotenoids. Process. Biochem. 46, 210-218.

Sitepu, I.R., Sestric, R., Ignatia, L., Levin, D., German, J.B., Gillies, L.A., Almada, L.A.G.,
Boundy-Mills, K.L., 2013. Manipulation of culture conditions alters lipid content and fatty acid profiles of a wide variety of known and new oleaginous yeast species. Bioresour. Technol. 144, 360-369.

Sitepu, I.R., Garay, L.A., Sestric, R., Levin, D., Block, D.E., German, J.B., Boundy-Mills, K.L., 2014. Oleaginous yeasts for biodiesel: current and future trends in biology and production. Biotechnol. Adv. 32, 1336-1360.

Su, Y., Gamero, A., Rodríguez, M.E., Lopes, C.A., Querol, A., Guillamón, J.M., 2019. Interspecific hybridisation among diverse Saccharomyces species: a combined biotechnological solution for low-temperature and nitrogen-limited wine fermentations. Int. J. Food Microbiol. 310, 108331.

Subramaniam, R., Dufreche, S., Zappi, M., Bajpai, R., 2010. Microbial lipids from renewable resources: production and characterization. J. Ind. Microbiol. Biotechnol $37,1271-1287$.

Taskin, M., Saghafian, A., Aydogan, M.N., Arslan, N.P., 2015. Microbial lipid production by cold-adapted oleaginous yeast Yarrowia lipolytica B9 in non-sterile whey medium. Biofuels Bioprod. Biorefining 9, 595-605.

Turcotte, G., Kosaric, N., 1989. The effect of C/N ratio on lipid production by Rhodosporidium toruloides ATCC 10788. Biotechnol. Lett. 11, 637-642.

Villegas, L.B., Amoroso, M.J., de Figueroa, L.I.C., 2005. Copper tolerant yeasts isolated from polluted area of Argentina. J. Basic Microbiol. 45, 381-391.

Viñarta, S.C., Angelicola, M.V., Barros, J.M., Fernández, P.M., Mac Cormak, W., Aybar, M.J., de Figueroa, L.I.C., 2016. Oleaginous yeasts from Antarctica: screening and preliminary approach on lipid accumulation. J. Basic Microbiol. 56, 1360-1368.

Zhu, Z., Zhang, S., Liu, H., Shen, H., Lin, X., Yang, F., Zhou, Y.J., Jin, G., Ye, M., Zou, H., Zhao, Z.K., 2012. A multi-omic map of the lipid-producing yeast Rhodosporidium toruloides. Nat. Commun. 3, 1112. 